УДК 338

$10.17213 / 2075-2067-2021-1-114-121$

\title{
ПЕРСПЕКТИВНЫЕ НАПРАВЛЕНИЯ РАЗВИТИЯ ЛОГИСТИЧЕСКИХ СИСТЕМ В УСЛОВИЯХ ПАНДЕМИИ COVID-19
}

\author{
(C) 2021 г. А. У. Альбеков, Т. В. Пархоменко
}

\author{
Ростовский государственный экономический университет (РИНХ), \\ 2. Ростов-на-Дону, Россия
}

Целью исследования является изучение вопросов, связанных с анализом и упорядочением изменений места и значения логистики и управления цепями поставок в противостоянии негативным последствиям пандемии, выявлением трендов и тенденций, которые свойственны логистике нового формата в условиях пандемии.

Методологическая база исследования. В рамках исследования вопросов оптимизации параметров логистических бизнес-процессов в условиях пандемии мы опираемся на рассмотрение профильных литературных источников, характеризующих динамику произошедших изменений и возникшей в результате вируса рецессии экономики как очередного кризиса, материалы по текущей экономической ситуации, в том числе отражающие зарубежный опыт. Использовались общенаучные методы исследования: описательный, сравнительного анализа и синтеза полученной информации.

Результаты исследования. Одним из важных результатов является определение характеристик и особенностей функционирования и развития логистических систем в условиях пандемии, анализ и систематизаџия произошедших изменений, выявление трендов и тенденций, которые свойственны логистике и управлению цепями поставок в новом формате, выявление перспективных направлений роста логистических систем распределения.

Перспективу исследования составляет доказательный анализ возможностей логистики обеспечивать бесперебойность поставок, способность логистических провайдеров, функиионирующих на отраслевых и территориальных рынках, адаптироваться к изменившимся условиям, оперативно реагируя на перемены внешней среды.

Ключевые слова: логистика; пандемия COVID-19; управление цепями поставок.

\section{PROSPECTIVE DIRECTIONS OF LOGISTICS SYSTEMS DEVELOPMENT IN THE COVID-19 PANDEMIC}

\section{(C) 2021 A. U. Albekov, T. V. Parkhomenko}

\section{Rostov State University of Economics (RSUE), Rostov-on-Don, Russia}

The purpose of the research is a study of issues related to the analysis and ordering of changes in the place and significance of logistics and supply chain management in confronting the negative consequences of a pandemic, identifying trends and trends that are characteristic of the logistics of a new format in a pandemic.

The methodological base of the study. As part of the study of optimization of the parameters of logistics business processes in a pandemic, we rely on the consideration of specialized literary sources characterizing the dynamics of the changes that have occurred and the economic recession 
resulting from the virus, as another crisis, materials on the current economic situation, including those reflecting foreign experience. General scientific research methods were used: descriptive, comparative analysis and synthesis of the information obtained.

The results of the study. One of the important results is to determine the characteristics and features of the functioning and development of logistics systems in a pandemic, analyze and systematize the changes that have occurred, identify trends and tendencies that are characteristic of logistics and supply chain management in a new format, identify promising areas for the growth of logistics distribution systems.

The prospect of the study compiles an evidence-based analysis of logistics capabilities to ensure security of supply, the ability of logistics providers operating in sectoral and regional markets to adapt to changing conditions, quickly responding to changes in the external environment.

Key words: logistics; COVID-19 pandemic; supply chain management.

Введение. В начале 2020 года пандемия коронавируса существенно усложнила функционирование экономик и системы товарнотранспортного, логистического обеспечения государств всего мира. В первой-второй декаде всплеск заражения, пандемия, угроза здоровью и строгие ограничительные карантинные меры приостановили деятельность компаний и снизили спрос, что отрицательно сказалось на показателях выпуска продукции, занятости населения и объемах реализуемых товаров, о чем свидетельствуют данные рисунка 1.

Стремительное распространение COVID-19 на планете нанесло существенный удар по всем аспектам жизнедеятельности, изменив мир навсегда. Но сущностные характеристики, принесшие временную дестабилизацию, могут дать и определенное количество возможностей, которые скрыты под образовавшейся в начале года паникой, проявлениями социальной нестабильности и многими другими негативными последствиями. Постараемся исследовать, проанализировать и систематизировать произошедшие изменения, охарактеризовать тренды и тенденции, которые свойственны логистике и управлению цепями поставок в новом формате, в условиях пандемии.

Обсуждение. Рассматривая точки роста, возможности и перспективы оптимизации параметров логистических бизнес-процессов в условиях пандемии, необходимо представить характер и динамику произошедших изменений и возникшего в результате вируса рецессии экономики как очередного кризиса.
Фактически в мировой социально-экономической системе кризисы происходят с интервалом 5-10 лет, что подтверждает исследовательскую позицию в пользу того, что в 2020 году, возможно, будет зафиксирована очередная всемирная рецессия, согласно логистическому форсайтингу она как бы встроится в событийную закономерность XXI века.

Таблица 1 демонстрирует прогнозные значения роста экономики на 2020 год.

«Спад темпов роста экономики в развитых странах за текущий период оценивается Всемирным банком на уровне $7 \%$, МВФ на уровне $8 \%$, при этом он будет скачкобразным. Так, ВВП Японии сократится, по прогнозам МВФ, на 5,8\%, тогда как Италии и Испании - на 12,8\%» [1].

Прогноз ВВП 2020 года до COVID-19 и после в странах мира свидетельствует о сложности положения доминирующего числа государств, находящихся в верхней части диаграммы (рис. 2), среди них находится и Россия.

Рассматривая реалии сегодняшней экономической ситуации, место и значение логистики и управления цепями поставок в противостоянии негативным последствиям пандемии, представим более подробно прогнозные характеристики ВВП в мировом формате. Для примера приведем следующую диаграмму (рис. 3).

Анализируя представленную диаграмму, отметим, что все государства мира с большой вероятностью получат существенное падение показателя ВВП, но более всего текущий 
кризис коснулся европейских государств, Великобритании, Италии, Франции. Россия же в общем рейтинге падения ВВП выглядит относительно благополучно. Распространение COVID-19 породило глобальный, системный мировой кризис, не похожий ни на один из предыдущих. Прогнозы выхода из пандемии также не могут быть в данный момент рациональны и обоснованы, так как экономическая сторона вопроса в этом отношении тесно увязана с медицинскими показателями. Следует отметить, что российскими эпидемиологами уже разработана и апробирована вакцина, которая может эффективно применяться для борьбы с распространением инфекции COVID-19.
Представим более подробно прогнозные данные влияния COVID-19 на экономику Российской Федерации (рис. 4.)

«В представленных сценариях заметное ускорение темпов экономического роста в Российской Федерации возможно лишь при условии активизации инвестиционной активности в частном секторе экономики, что позволит увеличить структурные темпы роста за счет и расширения основного капитала, и развития совокупной факторной производительности (путем импорта и развития новых технологий)» [2, с. 2140].

Сильнее всего во втором квартале 2020 года, когда действовали карантинные ограничения, сократилась добавленная стои-

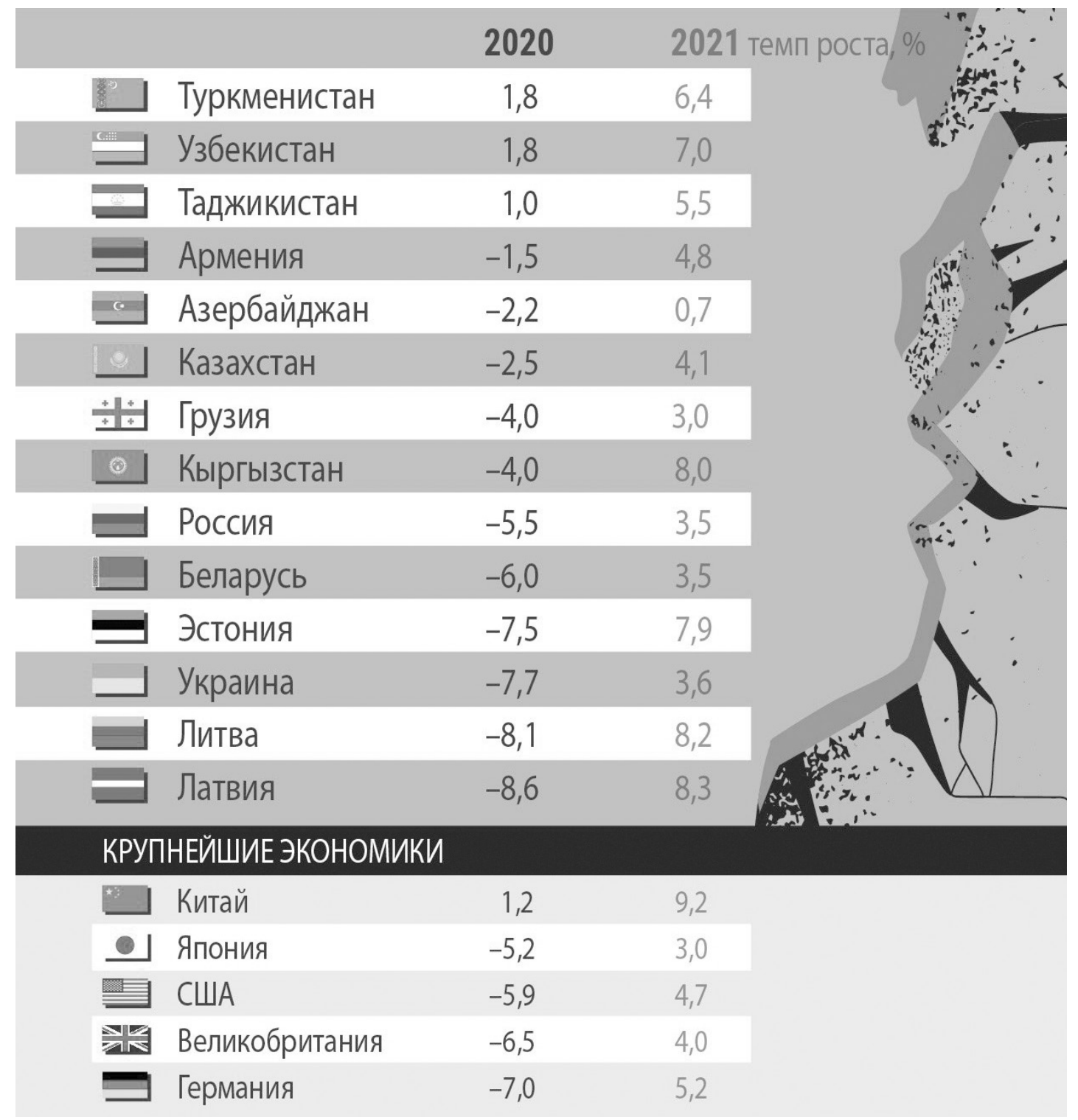

Рис. 1. Темпы роста экономик мира [3] 
Прогнозы темпов роста мировой экономики на 2020 год [1]

\begin{tabular}{|l|c|c|c|c|c|c|}
\hline \multicolumn{7}{|c|}{ Прогноз на 2020 год, в \% к 2019 году } \\
\hline \multirow{2}{*}{ Всемирный банк } & \multicolumn{3}{c|}{ МВФ } & $\begin{array}{c}\text { Американское рейтинговое } \\
\text { агентство Fitch }\end{array}$ \\
\hline Прогноз от 08.01.20 & $\begin{array}{c}\text { Прогно3 } \\
\text { от 08.06.20 }\end{array}$ & $\begin{array}{c}\text { Прогно3 } \\
\text { от 14.04.20 }\end{array}$ & $\begin{array}{c}\text { Прогно3 } \\
\text { от 24.06.20 }\end{array}$ & $\begin{array}{c}\text { Прогно3 } \\
\text { от 26.06.20 }\end{array}$ & $\begin{array}{c}\text { Прогно3 } \\
\text { от 29.07.20 }\end{array}$ \\
\hline Мир & 2,5 & & $-3,0$ & $-4,9$ & $-4,6$ & $-4,6$ \\
\hline США & 1,8 & $-6,1$ & $-5,9$ & $-8,0$ & $-5,6$ & $-5,6$ \\
\hline Япония & 0,7 & $-6,1$ & $-5,2$ & $-5,8$ & $-5,0$ & $-5,0$ \\
\hline Германия & - & - & $-7,0$ & $-7,8$ & $-6,7$ & $-6,3$ \\
\hline Франция & - & - & $-7,2$ & $-12,5$ & $-9,0$ & $-9,0$ \\
\hline Италия & - & - & $-9,1$ & $-12,8$ & $-9,5$ & $-9,5$ \\
\hline Испания & - & - & $-8,0$ & $-12,8$ & $-9,6$ & $-9,6$ \\
\hline Великобритания & - & - & $-6,5$ & $-10,2$ & $-7,8$ & $-9,0$ \\
\hline Еврозона & 1 & $-9,1$ & $-7,5$ & $-10,2$ & $-8,2$ & $-8,0$ \\
\hline Россия & 0,9 & $-7,1$ & $-5,8$ & $-8,0$ & $-5,5$ & $-6,7$ \\
\hline Китай & 5,9 & 1 & 1,2 & 1 & 0,7 & 1,2 \\
\hline
\end{tabular}

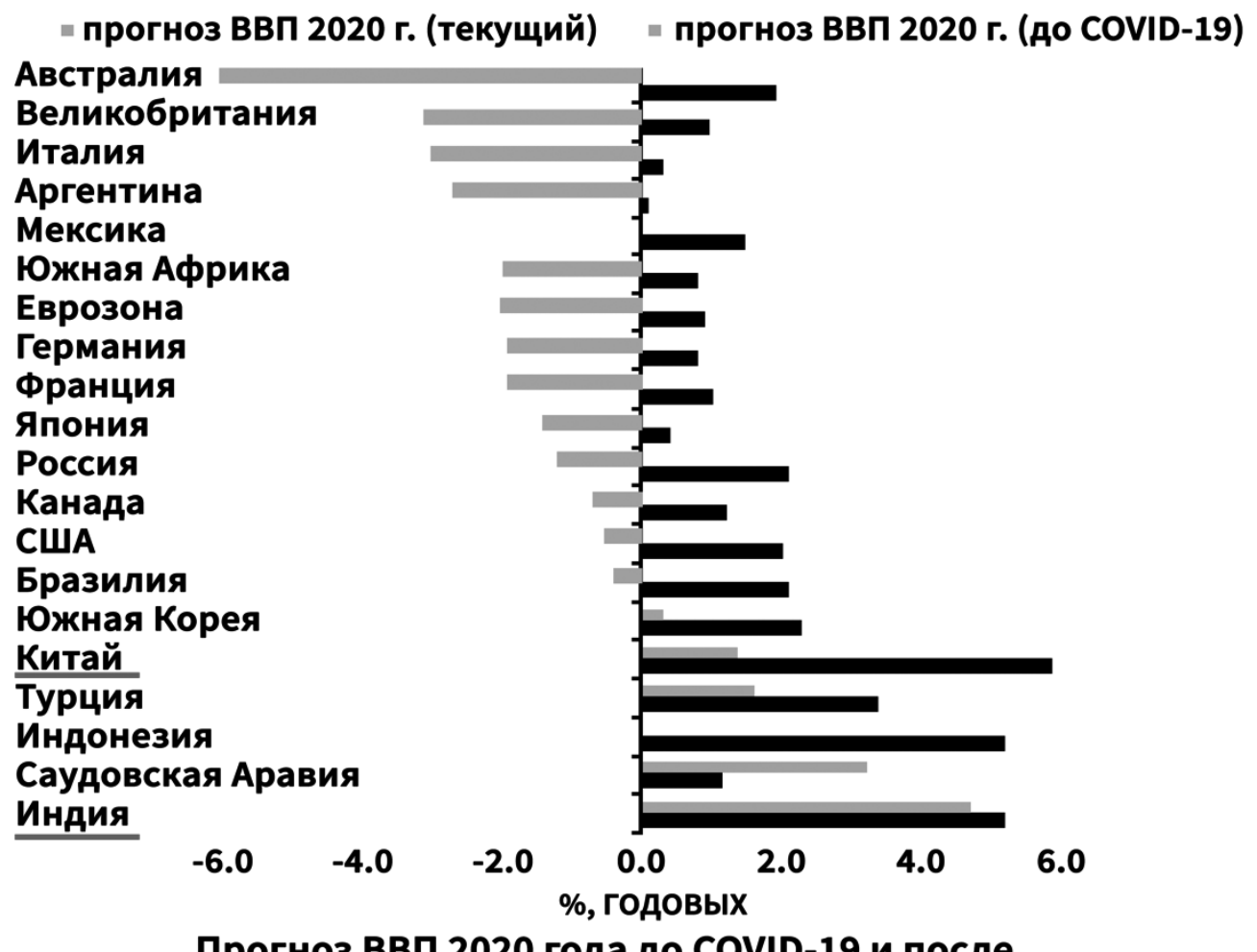

Рис. 2. Прогноз ВВП 2020 года до COVID-19 и после в странах мира [2] 
мость в отраслях сервисной экономики в России, в том числе: $(-56,9 \%)$;

- деятельность гостиниц и ресторанов

- деятельность в области культуры и спорта $(-28,0 \%)$;

- транспорт (-19,3\%);

— торговля $(-12,7 \%)$;

- прочие услуги населению (-28,6\%).

«Одновременно на фоне мирового сокращения спроса на энергоресурсы существенное падение наблюдалось в добывающей $(-12,8 \%)$ и обрабатывающей промышленностях $(-7,9 \%)$. Сектор здравоохранения сократился на $8,5 \%$ во втором квартале, что связано со значительным сокращением объема платных медицинских услуг. Финансовая и страховая деятельность, наоборот, показала прирост добавленной стоимости $(+6,1 \%)$ за счет роста банковской деятельности. Российские вкладчики во втором квартале не снижали свою активность, значительная часть финансовых услуг продолжала функционировать в онлайн-режиме. Просадка российской экономики из-за пандемии оказалась более умеренной относительно других стран. Для сравнения: ВВП США во втором квартале рухнул на 9,5\% в годовом выражении, ВВП Евросоюза - на 14,1\%, ВВП Испании — на 22\%, Франции — на 19\%, Италии - на 17,3\%. В России не так развита сервисная экономика, а доля малого и среднего бизнеса намного меньше, чем в США и странах Евросоюза. Малый и средний биз- нес в России формирует всего 20,2\% ВВП против около $80 \%$ в США» [4].

Результаты. Логистика как интегрированное планирование, организация и управление потоковыми процессами в современных научно-прикладных реалиях выступает основным катализатором изменений, происходящих в социально-экономических системах. Моделирование сетевой структуры цепей поставок и конфигурации логистических сетей в новых реалиях, ответ на вызовы пандемии в рамках противостоянию разрушения привычных схем жизнедеятельности, производства и распределения продукции также лежат в поле деятельности логистики.

Стремительное развитие коммерции онлайн-продаж, из-за пандемии предоставляющей покупателю возможность обеспечения доставки, существенно скорректировало логистические системы многоформатного ритейла, при этом изменился сам спрос, возник временный дисбаланс грузоперевозок (февраль-апрель 2020 г.) из-за ограничений пропускной способности и других запретов.

Снижение грузо- и особенно пассажиропотоков, наблюдающееся в глобальных форматах из-за за изоляции и понижения покупательской способности широких слоев населения, временная остановка промышленных и закрытие определенного числа коммерческих предприятий породили неопределенность и неуверенность в будущем населения

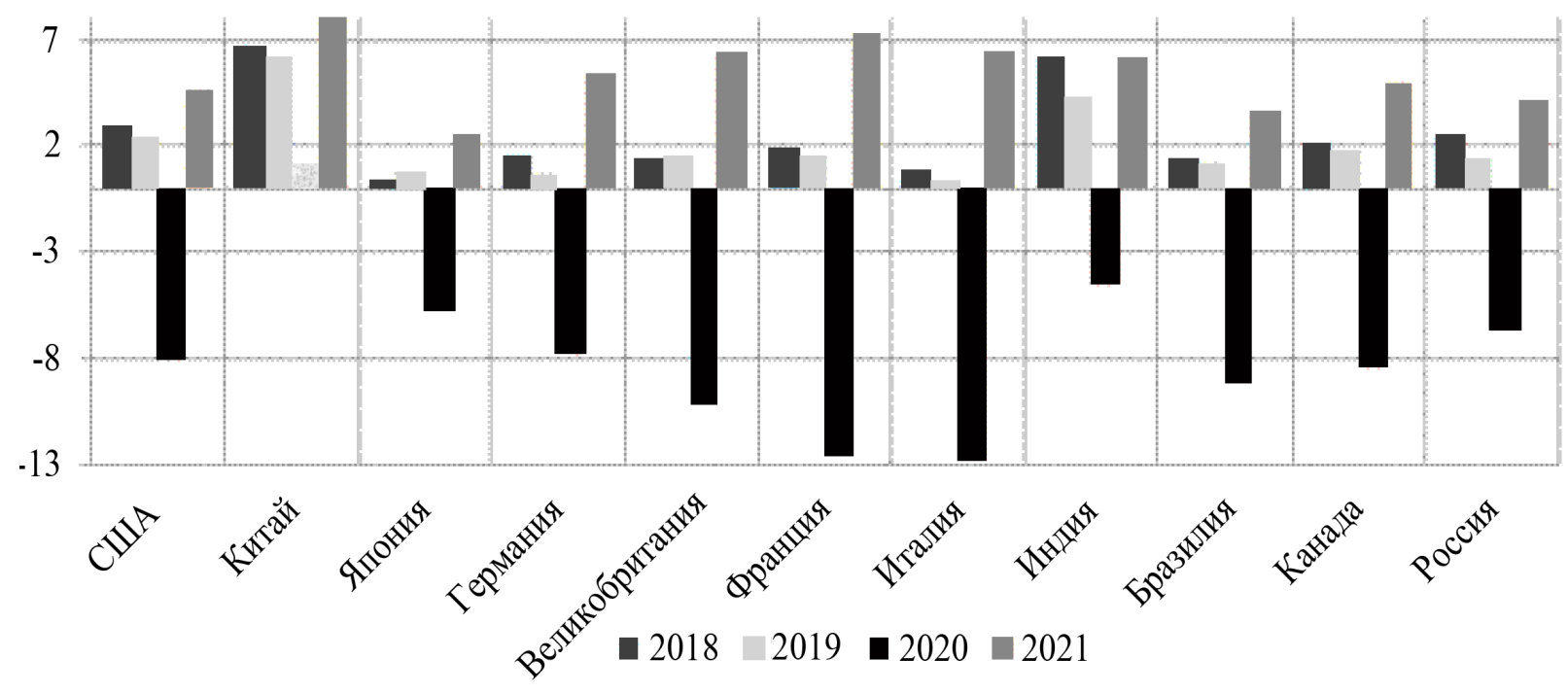

Рис. 3. Фактические и прогнозные характеристики показателей ВВП в мире [2] 
каждого государства. Но меры государственного регулирования логистических процессов в цепях поставок, поддержка отраслей специализации, малого и среднего бизнеca, налоговые каникулы, социальные дотации и иные льготы позволили поддержать не только российскую экономику, но и социальную сферу, обеспечив уверенность в завтрашнем дне.

Изначально деформировав стандартные логистические активности и изменив траектории движения потоков в устоявшихся форматах, пандемия внесла изменения в большинстве направлений деятельности логистических компаний. В рамках изменившихся условий были заморожены крупные логистические проекты, сократились объемы грузоперевозок с Европой и Азией, но при этом рынок в целом и логистика как ключевой элемент, обладающий высокой коммерческой и социальной значимостью, достаточно быстро привыкли к произошедшим в одночасье переменам, демонстрируя свойства адаптивности, гибридности и рационализации.

Заключение. Концептуальные исследования в области логистики и управления цепями поставок в период пандемии, несомненно, должны учитывать существенный рост электронной торговли, так как инновационные цифровые модели бизнес-логисти-

БАЗОВЫЙ СЦЕНАРИЙ

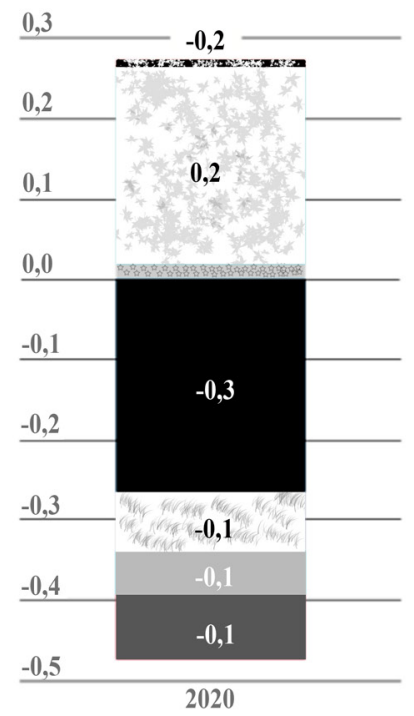

ческого взаимодействия, демонстрирующие увеличение каждый год, в 2020 году смогли опровергнуть все прогнозы. Увеличение онлайн-продаж на уровне до $30 \%$ - такой бифуркальный скачок предположить было невозможно. Рассматривая теоретико-прикладную модель роста логистических операций в мире, следует констатировать существенные возможности роста эффективных логистических концепций, которые позволяют осуществлять доставку в сжатые сроки. Пандемия COVID-19 существенно ускорила развитие электронных платформ и онлайнсервисов, определила увеличение объемов электронной коммерции и логистики в долгосрочной перспективе.

В российской логистической системе обеспечения онлайн-продаж существенно набирают обороты новые категории, например, продукты питания, детские и бытовые товары, мебель. Изменение потребительских привычек, вызванное распространением инфекции и самоизоляцией, укоренились и останутся в формате возможности надолго.

Временная турбулентность логистики осталась в прошлом вместе с активной фазой кризиса социально-экономических систем. Обеспечивая бесперебойность поставок, большинство логистических компаний, провайдеров, функционирующих на разных отраслевых и территориальных рынках, смогли

\section{КРИЗИСНЫЙ СЦЕНАРИЙ}

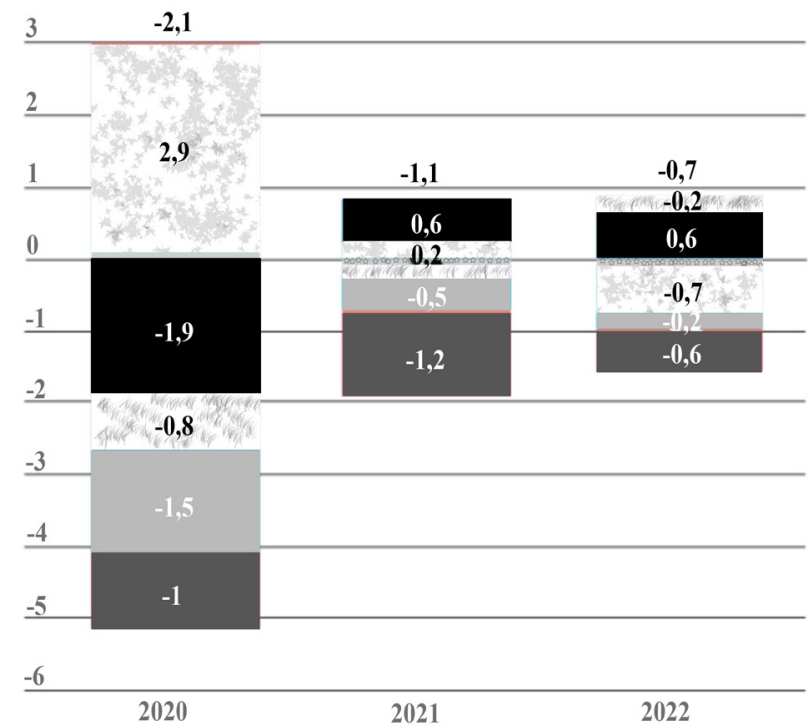

Рис. 4. Как повлияет COVID-19 на экономику Российской Федерации, в базовом и кризисном сценариях [2] 
адаптироваться к изменившимся условиям, оперативно реагируя на перемены внешней среды, определить и использовать возможные точки роста.

\section{Литература}

1. Азиатский банк инфраструктурных инвестиций (АБИИ) [Электронный ресурс]. Режим доступа: http://russian.china.org. cn>china>content_75671811 (Дата обращения: 12.12.2020).

2. Дробот Е.В., Макаров И.Н., Назаренко В.С., Манасян С.M. Влияние пандемии COVID-19 на реальный сектор экономики// Экономика, предпринимательство и право. 2020. 一 T. 10. — №8. - C. 2135-2150. — DOI: 10.18334/epp.10.8.110790.

3. Мировой кризис 2020: вызовы для мира и ЕАЭС. Опыт выхода из кризиса 2014/15 годов. Аналитическая записка по состоянию на 31.03.20 [Электронный ресурс]. — Режим доступа: http://www.eurasiancommission.org/ ru/covid-19/Documents/2222.pdf (Дата обращения: 12.12.2020).

4. Росстат уменьшил оценку падения ВВП на пике пандемии. Почему коронакризис меньше затронул Россию, чем другие страны. РБК [Электронный ресурс]. — Pежим доступа: https://www.rbc.ru/economics/0 9/09/2020/5f58e8699a794783405417fc (Дата обращения: 12.12.2020).

\section{References}

1. Aziatskij bank infrastrukturnyh investicij (ABII) [Asian Infrastructure Investment Bank (AIIB)] [Jelektronnyj resurs]. — URL: http:// russian.china.org.cn $>$ china $>$ content_75671811 (Date accessed: 12.12.2020).

2. Drobot E.V., Makarov I.N., Nazarenko V.S., Manasjan S.M. Vlijanie pandemii COVID-19 na real'nyj sektor jekonomiki [The impact of the COVID-19 pandemic on the real sector of the economy] // Jekonomika, predprinimatel'stvo i pravo [Economics, Entrepreneurship and Law]. 2020. - Vol. 10. — №8. - Pp. 2135-2150. DOI: $10.18334 /$ epp.10.8.110790.

3. Mirovoj krizis 2020: vyzovy dlja mira i EAJeS. Opyt vyhoda iz krizisa 2014/15 godov. Analiticheskaja zapiska po sostojaniju na 31.03.20 [World Crisis 2020: Challenges for the world and the EAEU. Experience of recovery from the 2014/15 crisis. Analytical note as of 31.03.20] [Jelektronnyj resurs]. — URL: http:// www.eurasiancommission.org/ru/covid-19/Documents/2222.pdf (Date accessed: 12.12.2020).

4. Rosstat umen'shil ocenku padenija VVP na pike pandemii. Pochemu koronakrizis men'she zatronul Rossiju, chem drugie strany. RBK [Rosstat has reduced the estimate of the fall in GDP at the peak of the pandemic. Why the coronacrisis affected Russia less than other countries. RBC] [Jelektronnyj resurs]. — URL: https://www.rbc. ru/economics/09/09/2020/5f58e8699a79478340 5417fc (Date accessed: 12.12.2020). 


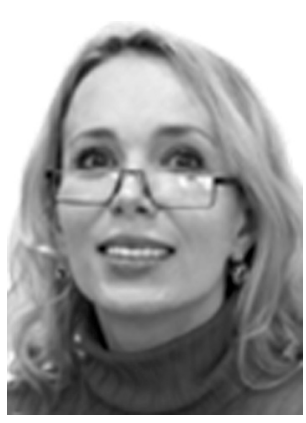

Пархоменко Татьяна Валерьевна - доктор экономических наук, профессор кафедры «Коммерция и логистика» Ростовского государственного экономического университета (РИНХ).

Parkhomenko Tatyana Valeriyevna - Doctor of Economic Sciences, Professor, Commerce and Logistics Department, Rostov State University of Economics (RSUE).

344002, г. Ростов-на-Дону, ул. Б. Садовая, 69 69 B. Sadovaya st., 344002, Rostov-on-Don, Russia E-mail: inrost@list.ru

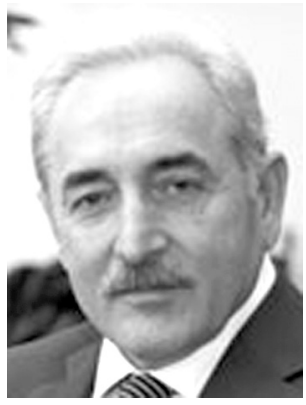

Альбеков Адам Умарович - доктор экономических наук, профессор, президент Ростовского государственного экономического университета (РИНХ).

Albekov Adam Umarovich - Doctor of Economic Sciences, Professor, President, Rostov State University of Economics (RSUE).

344002, г. Ростов-на-Дону, ул. Б. Садовая, 69 69 B. Sadovaya st., 344002, Rostov-on-Don, Russia E-mail: a2404929@yandex.ru 